\title{
Implantable collamer lens with central hole: 3-year follow-up
}

\author{
Luis Fernández-Vega- \\ Cueto' \\ Carlos Lisa' \\ José J Esteve-Taboada ${ }^{2}$ \\ Robert Montés-Micó ${ }^{2}$ \\ José F Alfonso ${ }^{1,3}$ \\ 'Department of Surgery, Fernández- \\ Vega Ophthalmological Institute, \\ Oviedo, Spain; ${ }^{2}$ Department of Optics \\ and Optometry and Visual Sciences, \\ University of Valencia, Valencia, Spain; \\ ${ }^{3}$ School of Medicine, University of \\ Oviedo, Oviedo, Spain
}

This article was published in the following Dove Press journal: Clinical Ophthalmology
Purpose: To evaluate the long-term predictability, stability, safety, and efficacy of the V4c Visian implantable collamer lens (ICL) with central hole to correct myopia.

Patients and methods: One hundred and eighty-four eyes of 92 patients were evaluated during 3 years after implantation of the V4c ICL. The refraction, uncorrected distance visual acuity, best-corrected distance visual acuity, IOP, endothelial cell count, vault, and adverse effects were evaluated every 12 months during the whole follow-up.

Results: The mean spherical equivalent dropped from $-8.30 \pm 2.98 \mathrm{D}$ preoperatively to $-0.37 \pm 0.47 \mathrm{D}$ at 36 months post-surgery, with $91.8 \%$ eyes being within $\pm 1.00 \mathrm{D}$ of emmetropia. With respect to the astigmatic components $\mathrm{J} 0$ and $\mathrm{J} 45,98.4 \%$ and $99.5 \%$ of eyes, respectively, were within $\pm 0.50 \mathrm{D}$ of the desired refraction. At 36 months, $78.8 \%$ of eyes had no change in the Snellen lines of best-corrected distance visual acuity, while $8.7 \%$ gained one line and $6.5 \%$ gained two or more lines; mean safety and efficacy indexes were 1.03 and 0.90 , respectively. Mean endothelial cell count was $2,742 \pm 340$ cells $/ \mathrm{mm}^{2}$ before and $2,663 \pm 366$ cells $/ \mathrm{mm}^{2}$ at 36 months post-surgery. Mean IOP reduced from $13.7 \pm 1.9 \mathrm{mmHg}$ preoperatively to $12.8 \pm 1.7 \mathrm{mmHg}$ at 36 months post-surgery. Mean vault varied from $409 \pm 196 \mu \mathrm{m}$ at 12 months to $349 \pm 165 \mu \mathrm{m}$ at 36 months.

Conclusion: The visual and refractive outcomes were very good and highly stable throughout the follow-up period, indicating that this ICL model may be predictable, stable, safe, and effective to correct myopia in the long term.

Keywords: phakic intraocular lens, implantable collamer lens, Visian ICL, long-term evaluation

\section{Introduction}

Phakic intraocular lens ( $\mathrm{pIOL}$ ) implantation is a precise and a reproducible technique that is widely used in patients with moderate to high ametropias who do not wish to have a corneal refractive procedure or have a contraindication for corneal refractive surgery. ${ }^{1,2}$

The Visian implantable collamer lens (ICL) (Staar Surgical AG, Nidau, Switzerland), which is a posterior chamber pIOL for the treatment of myopia, hyperopia, and astigmatism, has shown excellent outcomes of visual quality, stability, safety, predictability, and effectiveness to correct moderate to severe ametropias. ${ }^{3-11}$ Nevertheless, several complications after ICL implantation have also been reported. ${ }^{12}$ These complications include increased IOP, ${ }^{13}$ which is usually associated with acute pupillary block ${ }^{14}$ or with chronic pigment dispersion, and could be related to inadequate preoperative or intraoperative iridectomies. In addition, anterior subcapsular cataract $^{15-19}$ could appear as a result of ICL and crystalline lens contact because of an insufficient vault (central separation between the ICL and the crystalline lens) or due
Instituto Oftalmológico Fernández-Vega,

Avda Dres Fernández-Vega II4, Oviedo,

330I2, Spain

Tel +34985245533

Fax +34985233288

Email j.alfonso@fernandez-vega.com
Clinical Ophthalmology 2018:12 2015-2029

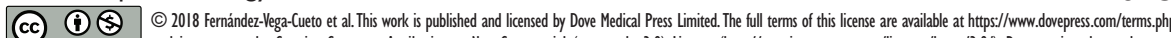

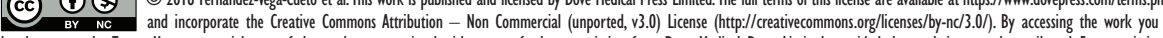
hereby accept the Terms. Non-commercial uses of the work are permitted without any further permission from Dove Medical Press Limited, provided the work is properly attributed. For peminsion for commercial use of this work, please see paragraphs 4.2 and 5 of our Terms (https://www.dovepress. con/terms.php). 
to a poor circulation of the aqueous humor induced by ICL implantation. ${ }^{20}$

The improved model V4c Visian ICL has been designed with a central hole of $0.36 \mathrm{~mm}$ (the KS-Aquaport) to overcome these disadvantages, allowing a more natural flow of the aqueous humor. With the central KS-Aquaport, the need to perform preoperative $\mathrm{Nd}$ :YAG peripheral iridotomies or intraoperative iridectomies is eliminated, reducing the overall procedure time and enhancing patients' comfort. The improvement of aqueous humor circulation reduces the incidence of cataracts. ${ }^{21,22}$ Some previous studies have shown that the ICL with central hole has no optical effect on vision, ${ }^{21-26}$ only one study related the possibility of ringshaped dysphotopsia after hole ICL implantation due to light refraction at the central hole structure. ${ }^{27}$ Simulation analyses and studies performed in porcine eyes have shown that the central hole increases the aqueous humor perfusion volume on the anterior surface of the crystalline lens, preventing the formation of lens opacities. ${ }^{28,29}$

The aim of this retrospective study was to assess the longterm clinical and refractive outcomes of the V4c Visian ICL with central hole model to correct moderate to high myopia over a 36-month period.

\section{Patients and methods}

This retrospective study included 184 eyes of 92 patients (30 male, 62 female) who had implantation of a V4c ICL model to correct myopia. Table 1 shows the preoperative patients' demographics and pIOL characteristics. All patients provided written informed consent after the nature

Table I Preoperative patient demographics and plOL characteristics

\begin{tabular}{|c|c|c|}
\hline Characteristic & Mean \pm SD & Range (min, max) \\
\hline Age (years) & $30.4 \pm 5.4$ & $(20,45)$ \\
\hline Refraction sphere (D) & $-7.95 \pm 2.91$ & $(-17.5,-2.5)$ \\
\hline Refraction cylinder (D) & $-0.69 \pm 0.62$ & $(-2.5,0)$ \\
\hline SE (D) & $-8.30 \pm 2.98$ & $(-18.25,-2.88)$ \\
\hline Corneal thickness $(\mu \mathrm{m})$ & $534 \pm 33$ & $(44 I, 60 I)$ \\
\hline $\mathrm{ACD}(\mathrm{mm})$ & $3.32 \pm 0.25$ & $(2.80,3.91)$ \\
\hline WTW@ @ $0^{\circ}(\mathrm{mm})$ & $12.02 \pm 0.45$ & $(11.00,13.45)$ \\
\hline WTW@ @90 (mm) & $12.38 \pm 0.45$ & $(11.09,13.49)$ \\
\hline $\mathrm{ECC}\left(\right.$ cells $\left./ \mathrm{mm}^{2}\right)$ & $2,742 \pm 340$ & $(2,040,3,903)$ \\
\hline IOP $(\mathrm{mmHg})$ & $13.7 \pm 1.9$ & $(8,19)$ \\
\hline Scotopic pupil size $(\mathrm{mm})$ & $6.74 \pm 0.86$ & $(4.5,8.5)$ \\
\hline Fotopic pupil size $(\mathrm{mm})$ & $4.87 \pm 0.89$ & $(3.0,7.0)$ \\
\hline plOL optical power (D) & $-9.1 I \pm 2.83$ & $(-18.0,-3.5)$ \\
\hline plOL size $(\mathrm{mm})$ & $13.2 \pm 0.3$ & $(12.6,13.7)$ \\
\hline
\end{tabular}

Abbreviations: ACD, anterior chamber depth; ECC, endothelial cell count; IOL, intraocular lens; pIOL, phakic IOL; SE, spherical equivalent; WTW, white to white. and the possible consequences of the study, approved by the Fernández-Vega Ophthalmological Institute Board, were explained to them fully in accordance with the Declaration of Helsinki.

The inclusion criteria were best-corrected distance visual acuity (CDVA) of 20/40 or better, stable refraction for 2 years, and clear central cornea. The exclusion criteria were age $<20$ years, anterior chamber depth $<2.8 \mathrm{~mm}$, endothelial cell count $(\mathrm{ECC})<2,000$ cells $/ \mathrm{mm}^{2}$, cataract, history of glaucoma or retinal detachment, macular degeneration or retinopathy, neuro-ophthalmic diseases, and history of ocular inflammation.

Before surgery, all patients had a complete ophthalmologic examination. The evaluation included manifest and cycloplegic refractions, keratometry, corneal topography, ECC, pachymetry (Orbscan II; Bausch \& Lomb, Rochester, NY, USA), slit-lamp microscopy, Goldmann applanation tonometry, and binocular indirect ophthalmoscopy through a dilated pupil. The target was emmetropia in all cases.

\section{pIOL size and power calculation}

The V4c Visian ICL with central hole is a phakic lens made from collamer (Staar Surgical AG proprietary), a flexible, hydrophilic, and biocompatible material with a plate-haptic design and a central convex/concave optical zone. The ICLs are foldable, allowing for posterior chamber injection through a microscopic incision of $3.5 \mathrm{~mm}$ or smaller. When properly placed, the ICL should be positioned completely within the posterior chamber between the iris and crystalline lens with support on the ciliary sulcus. In the present study, we analyzed the V4c ICL model, which introduces a central hole to avoid the peripheral iridectomies and increase the aqueous humor perfusion, thereby reducing the risk of secondary cataract formation. ${ }^{21,22}$ pIOL power calculation is performed using the software provide by the manufacturer. White-to-white and anterior chamber depth distances were measured in order to determine the appropriate size of the ICL. The mean optical power of the V4c ICL implanted in the sample of the study was $-9.11 \pm 2.83 \mathrm{D}$, range $(-18.0,-3.5)$, and the lens sizes chosen for all patients were $12.6,13.2$, or $13.7 \mathrm{~mm}$.

\section{Surgical technique}

All surgeries were performed by the same experienced surgeon (JFA) on the steep meridian through a 3.0-3.4 $\mathrm{mm}$ clear tunnel incision, as a function of the astigmatism (3.0 mm for $0.75 \mathrm{D}, 3.2 \mathrm{~mm}$ for $1.0 \mathrm{D}, 3.4 \mathrm{~mm}$ for $1.25 \mathrm{D}$ ), using peribulbar anesthesia. Thirty minutes before surgery, cycloplegic and phenylephrine eye drops were applied. Five 
minutes before surgery, povidone-iodine 5\% was applied. The anterior chamber was filled with sodium hyaluronate $1 \%$, which was completely removed at the end of the surgery. The lens was inserted using the ICL injector. Tobramycin and dexamethasone $0.1 \%$ eye drops were used four times a day for 10 days, after which diclofenac sodium eye drops were started four times a day for 2 weeks. The second eye had surgery during the first postoperative week of the first eye. All eyes were targeted for emmetropia. Figure 1 shows an example of a lens implanted in one of the patients included in this study.

\section{Follow-up}

Follow-up visits were done at 1 day, 1 week, and 1, 3, 12, 24 , and 36 months, although this manuscript reports results obtained at long term in 12, 24, and 36 months of follow-up. The examinations included uncorrected distance visual acuity (UDVA), CDVA, refractive status, slit-lamp examination, tonometry, ECC, and vault measured by the anterior segment optical coherence tomographer Visante. The vault between the crystalline lens and the ICL was measured perpendicular to the lens apex or at the narrowest space between both. During the follow-up period after surgery, two patients had to undergo ICL rotation after implantation due to high vault (greater than 1,200 $\mu \mathrm{m}$ ). Two patients underwent postoperative refraction correction by means of LASIK with optimized excimer laser at 24 and 36 months, respectively. No additional intraoperative complications were reported in other patients and there were no cases of pIOL decentration.

Assessment of outcomes was based on preoperative vs postoperative CDVA and UDVA values (efficacy and safety indexes), the achieved vs the expected postoperative refractive outcomes (predictability), and the refractive outcomes

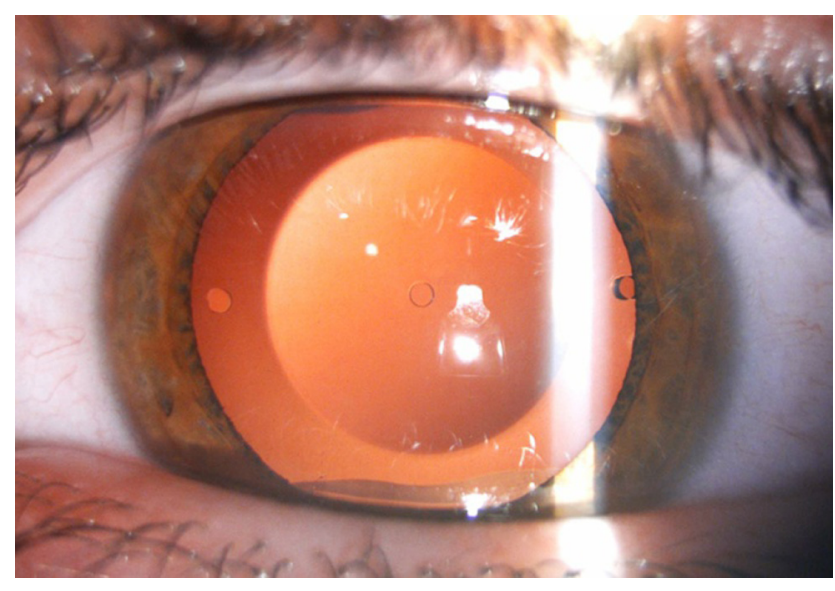

Figure I Example of a lens implanted in one of the patients. variability during the postoperative follow-up period (stability). The efficacy index (defined as the ratio between the postoperative UDVA and the preoperative CDVA) and the safety index (defined as the ratio between the postoperative CDVA and the preoperative CDVA) were also calculated based on Snellen decimal visual acuity values. Manifest refractions were recorded in conventional script notation (sphere S, cylinder $\mathrm{C}$, axis $\alpha$ ) and then converted to power vector coordinates by the following formulas: ${ }^{30}$

$$
\begin{gathered}
\mathrm{M}=\mathrm{S}+\mathrm{C} / 2 \\
\mathrm{~J} 0=(-\mathrm{C} / 2) \cos (2 \alpha) \\
\mathrm{J} 45=(-\mathrm{C} / 2) \sin (2 \alpha)
\end{gathered}
$$

where $\mathrm{M}$ is equal to the spherical equivalent (SE) of the given refractive error, J0 is the Jackson cross-cylinder with axes at $180^{\circ}$ and $90^{\circ}$, and $\mathrm{J} 45$ is the Jackson cross-cylinder with axes at $45^{\circ}$ and $135^{\circ}$.

\section{Statistical analysis}

Data analysis was performed using Excel (version 2016; Microsoft Corporation, Redmond, WA, USA) and statistical analysis was performed using SPSS statistical software (version 24.0; IBM Corp., Armonk, NY, USA). A repeatedmeasure ANOVA (rANOVA) was performed to reveal significant differences through the follow-up period. The normality of all data sets was evaluated by means of the Shapiro-Wilk test. The ANOVA procedure based on the $F$ statistic is robust under the breach of the normality assumption, provided that the data samples have no important asymmetries or similar distribution shapes. ${ }^{31}$ Prior to the rANOVA, the sphericity assumption was checked using the Mauchly's sphericity test. In cases in which sphericity could not be assumed, the Greenhouse-Geisser correction was applied..$^{32}$ The Bonferroni procedure was used as a post hoc test for comparisons between data groups when the rANOVA revealed significant differences between measurements. This method allows for obtaining the significance level for paired differences between the individual conditions. The statistical significance limit was set to $P<0.05$ in all cases.

\section{Results Predictability}

Figure 2 shows the achieved vs attempted refraction plots for $\mathrm{M}, \mathrm{J} 0$, and $\mathrm{J} 45$ at 12,24 , and 36 months postoperatively. The dashed lines in the plots represent the equality lines achieved refraction $=$ attempted refraction, while the two solid lines that are parallel to the dashed lines are defined by $\pm 1 \mathrm{D}$. When 
evaluating the SE component, at 12 months, $90.7 \%$ of eyes were within \pm 0.50 D of emmetropia, while $98.4 \%$ were within \pm 1.00 D. At 24 months, $80.4 \%$ of eyes were within $\pm 0.50 \mathrm{D}$ of emmetropia, while $95.1 \%$ were within \pm 1.00 D. At 36 months, $74.5 \%$ of eyes were within \pm 0.50 D of emmetropia, while $91.8 \%$ were within $\pm 1.00 \mathrm{D}$.
With respect to the astigmatic components $\mathrm{J} 0$ and $\mathrm{J} 45$, Figure 3 shows the preoperative and 12, 24, and 36 months postoperative astigmatic components of the power vector represented by the two-dimensional vector (J0, J45). As can be seen in the figure, during the whole postoperative follow-up, the distribution of points is tighter around zero compared to
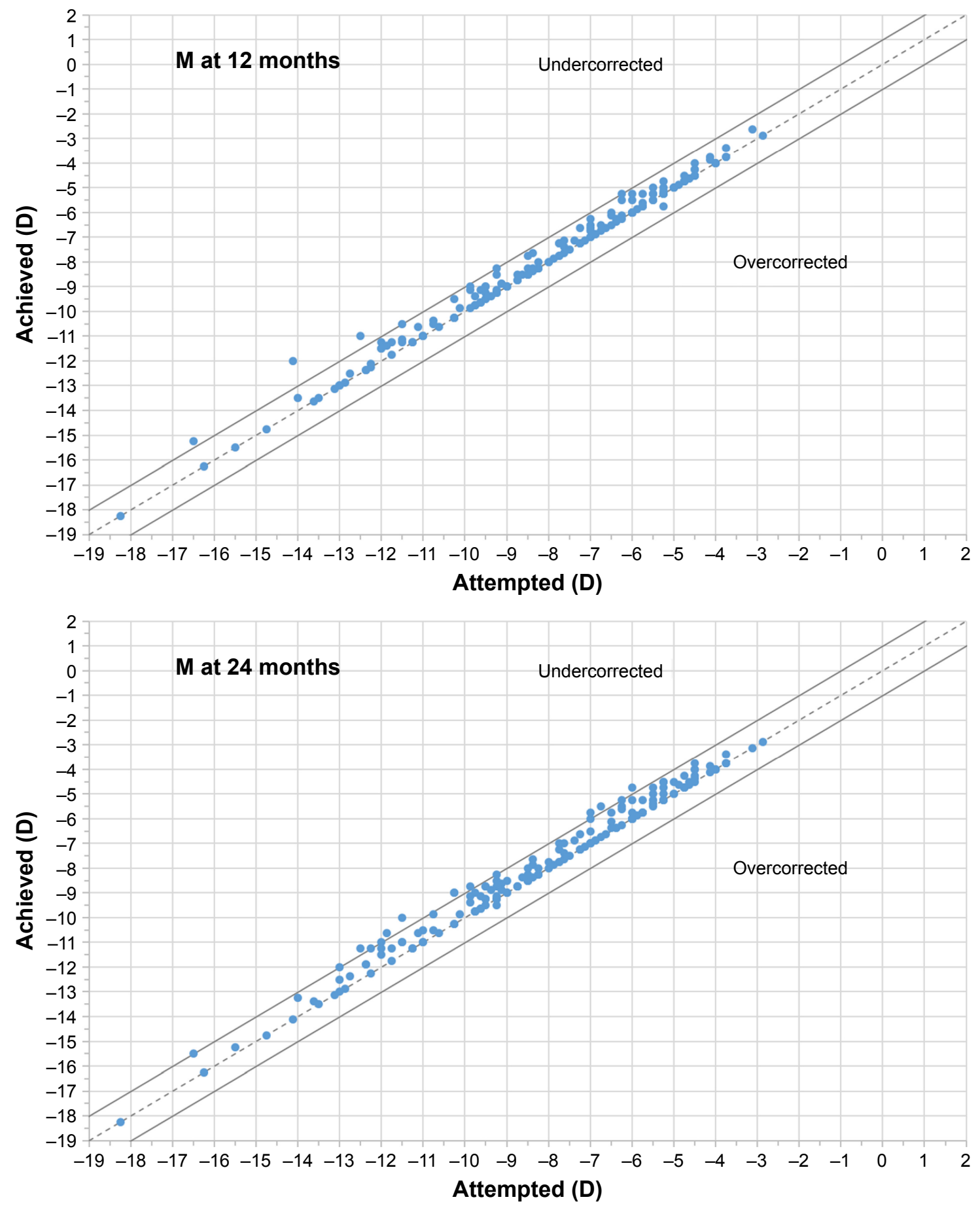

Figure 2 (Continued) 


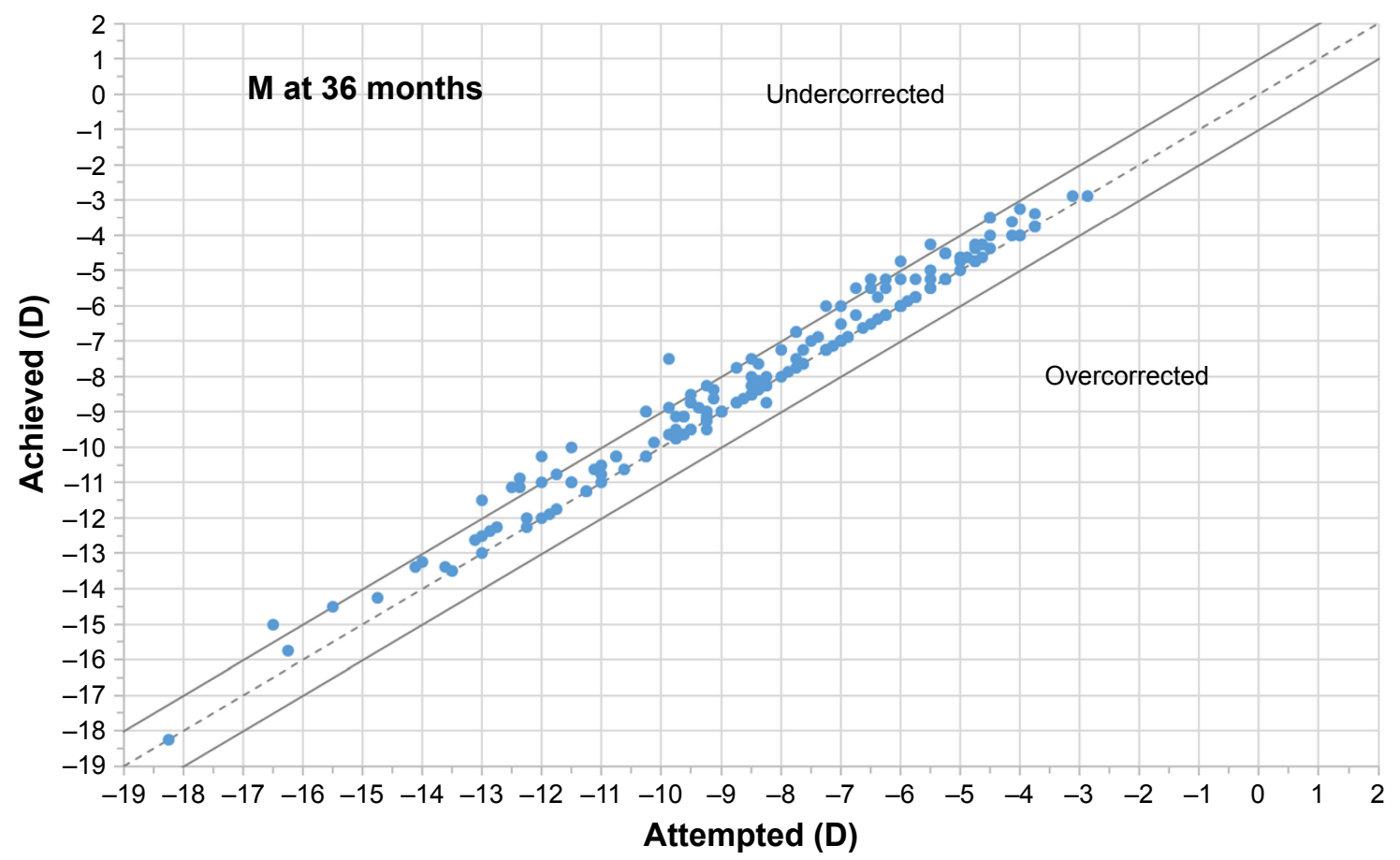

Figure 2 Plot of achieved vs attempted correction (predictability) for spherical equivalent (M) at 12, 24, and 36 months of follow-up.

the preoperative data (the origin in this graph represents an eye free of astigmatism). At 12 months, $97.8 \%$ and $99.5 \%$ of eyes were within $\pm 0.50 \mathrm{D}$ of the desired refraction for J0 and $\mathrm{J} 45$, respectively, while $98.9 \%$ and $100.0 \%$ of eyes were within $\pm 0.50 \mathrm{D}$ at 24 months and $98.4 \%$ and $99.5 \%$ were within $\pm 0.50 \mathrm{D}$ at 36 months.

\section{Stability}

The mean SE dropped from $-8.30 \pm 2.98 \mathrm{D}$ preoperatively to $-0.19 \pm 0.32,-0.29 \pm 0.38$, and $-0.37 \pm 0.47 \mathrm{D}$ at 12,24 , and 36 months post-surgery, respectively. The J0 component changed from $0.17 \pm 0.41 \mathrm{D}$ preoperatively to $0.04 \pm 0.31,0.03 \pm 0.29$, and $-0.01 \pm 0.29 \mathrm{D}$ at 12,24 , and 36 months post-surgery, respectively. The J45 component changed from $0.01 \pm 0.30 \mathrm{D}$ preoperatively to $-0.04 \pm 0.23$, $-0.04 \pm 0.22$, and $-0.05 \pm 0.21 \mathrm{D}$ at 12,24 , and 36 months post-surgery, respectively. The improvement in refractive error and refraction stability for $\mathrm{M}, \mathrm{J} 0$, and $\mathrm{J} 45$ during the 3 years of follow-up is shown in Figure 4. The change in SE from preoperative to 12,24 , and 36 months after surgery was statistically significant $(P<0.001)$.

\section{Safety}

Figure 5 shows the safety results at 12, 24, and 36 months postoperatively. At the end of the follow-up, 5.98\% (11 eyes) had lost one line of CDVA, 78.8\% (145 eyes) had no change from preoperatively, $8.7 \%$ (16 eyes) had gained one line of CDVA, $4.89 \%$ (9 eyes) had gained two lines, and $1.63 \%$ ( 3 eyes) had gained three or more lines. The mean safety index was 1.04, 1.03, and 1.03 for 12, 24, and 36 months postoperatively, respectively.

\section{Efficacy}

Figure 6 shows the cumulative proportion of eyes having a given UDVA value at 12, 24, and 36 months postoperatively. The UDVA was $20 / 20$ or better in 98 eyes $(56.0 \%, 175$ eyes measured) and $20 / 25$ or better in 132 eyes ( $75.4 \%$ ) at 3 years of follow-up, while preoperatively, all eyes had an UDVA worse than 20/63. Figure 7 shows the cumulative proportion of eyes having a given CDVA value, both preoperatively and at 12,24 , and 36 months postoperatively. The preoperative CDVA was 20/20 or better in 147 eyes ( $79.9 \%$ ) and 20/25 or better in 168 eyes (91.3\%), while the postoperative values at 36 months of follow-up increased to 161 eyes $(87.5 \%)$ and 175 eyes $(95.1 \%)$, respectively. The mean efficacy index was $0.99,0.92$, and 0.90 for 12,24 , and 36 months postoperatively, respectively.

\section{Intraocular pressure}

Figure 8 shows the evolution in the mean IOP for the whole follow-up period. The mean IOP had a significant small reduction from preoperatively to 12 months post-surgery 



J45 (D)

Figure 3 (Continued) 


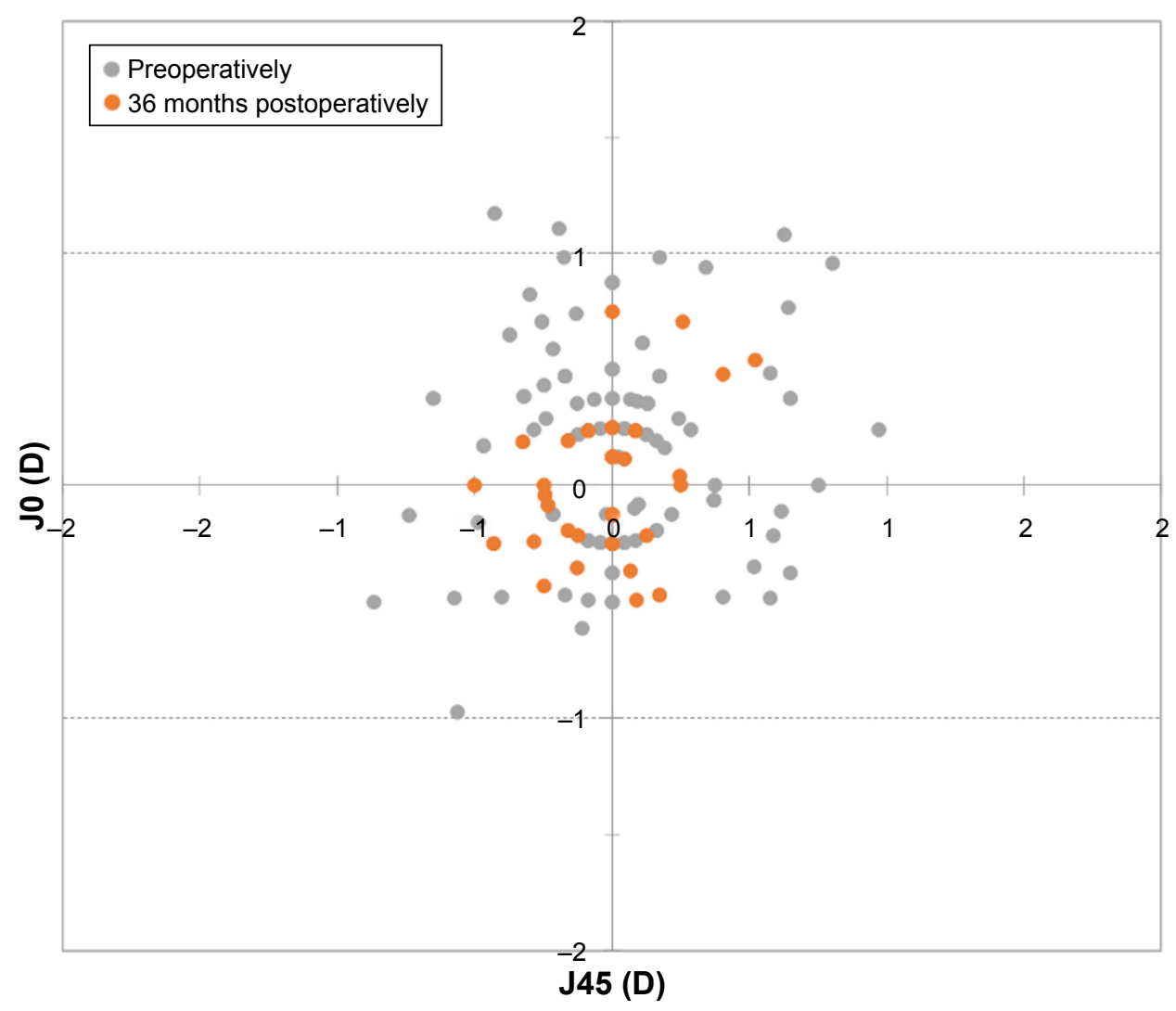

Figure 3 Preoperative and I2, 24, and 36 months postoperative astigmatic components of the power vector represented by the two-dimensional vector (J0, J45) (J0=Jackson cross-cylinder, axes at $180^{\circ}$ and $90^{\circ}$; $\mathrm{j} 45=$ Jackson cross-cylinder, axes at $45^{\circ}$ and $135^{\circ}$ ).

$(P<0.001)$ and was significantly stable $(P=1.0)$ during the rest of the follow-up period: $13.7 \pm 1.9 \mathrm{mmHg}$ preoperatively (182 eyes measured) to $12.8 \pm 1.5 \mathrm{mmHg}$ (177 eyes), $12.8 \pm 1.4$ $\mathrm{mmHg}$ (175 eyes), and $12.8 \pm 1.7 \mathrm{mmHg}$ (182 eyes) at 12,24 , and 36 months post-surgery, respectively.

\section{Endothelial cell count}

The mean preoperative ECC was $2,742 \pm 340$ cells $/ \mathrm{mm}^{2}$ (179 eyes measured), while the values obtained at 12, 24 , and 36 months post-surgery were $2,726 \pm 380,2,720 \pm 404$, and $2,663 \pm 366$ cells $/ \mathrm{mm}^{2}$, respectively (184 eyes in all cases). Figure 9 shows the temporal evolution of the mean ECC from the preoperative value to the 36 months post-surgery value. From the statistical point of view, the ECC values remained significantly stable during the whole follow-up period $(P=0.080)$.

\section{Vault}

The mean vault between the crystalline lens and the ICL changed significantly from $409 \pm 196 \mu \mathrm{m}$ at 12 months post-surgery to $357 \pm 178 \mu \mathrm{m}$ at 24 months of follow-up
$(P<0.001)$. This value was significantly stable $(P=0.311)$ from 24 months post-surgery to the value obtained at 36 months of follow-up $(349 \pm 165 \mu \mathrm{m})$. Figure 10 shows the evolution of mean vault values for the postoperative follow-up period (184 eyes measured in all cases).

\section{Discussion}

This retrospective study included 184 eyes of 92 patients who underwent V4c pIOL implantation. Its aim was to evaluate the long-term post-surgery results assessing whether this central hole-based model is safe, effective, and predictable in correcting myopia through 3 years of follow-up.

Several studies have been previously performed to evaluate the long-term refractive and visual stability related to the implantation of previous ICL models (V3, V4, V4 toric). ${ }^{33-35}$ Moya et $\mathrm{al}^{33}$ evaluated the long-term refractive results after the implantation of V3 and V4 ICL models for myopia, including in the retrospective study 144 eyes with clinical data available 12 years after the implantation. Mean SE refraction was $-16.90 \pm 4.26 \mathrm{D}$ preoperatively and $-1.77 \pm 1.93 \mathrm{D}$ at 12 years postoperatively. At the end 



Figure 4 Improvement in refractive error and refraction stability for M, J0, and J45 during the 3 years of follow-up. Error bars represent the SD.

Notes: $M$ is equal to the spherical equivalent of the given refractive error, $\mathrm{J} 0$ is the Jackson cross-cylinder with axes at $180^{\circ}$ and $90^{\circ}$, and $\mathrm{J} 45$ is the Jackson cross-cylinder with axes at $45^{\circ}$ and $135^{\circ}$. 

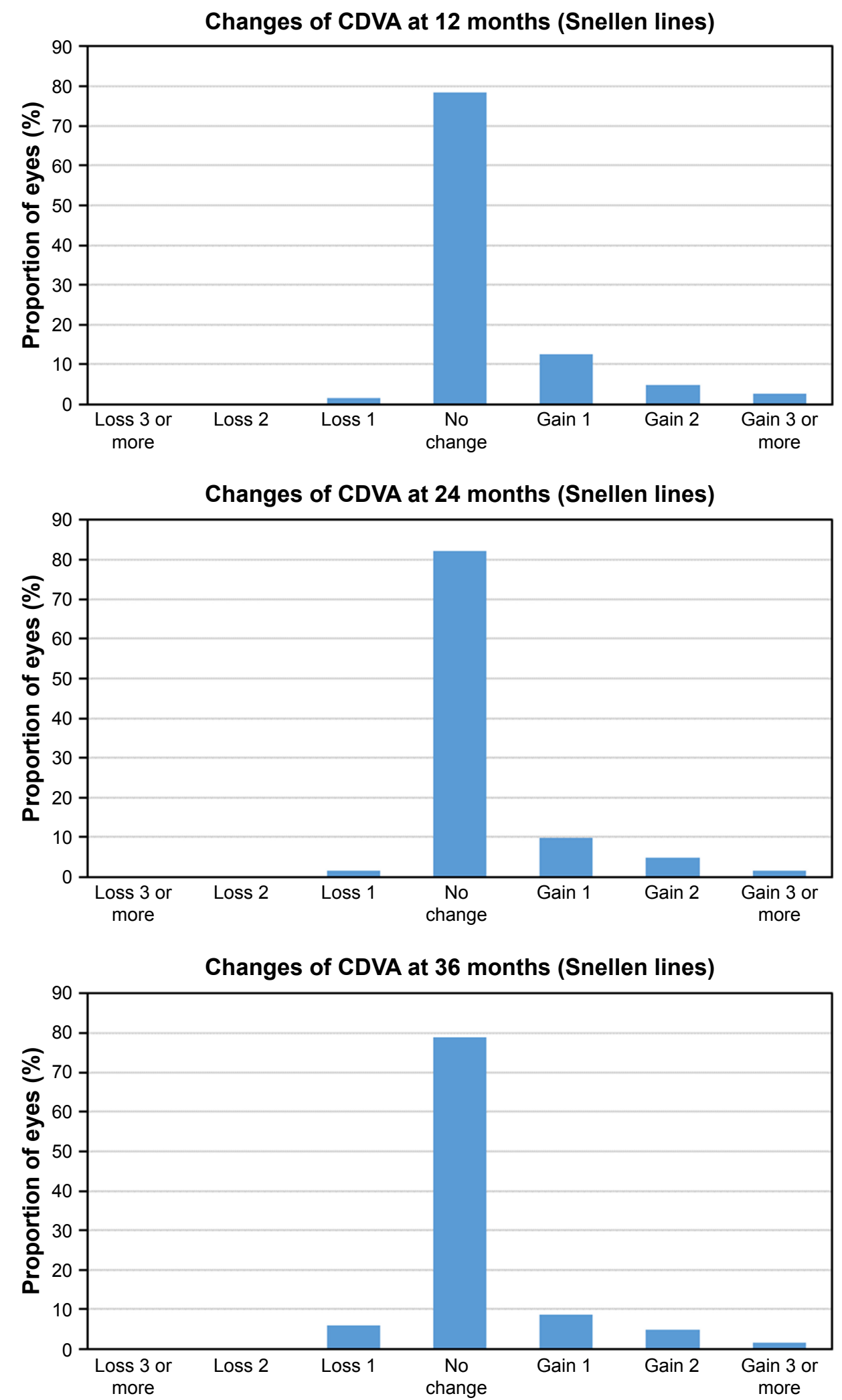

Figure 5 Postoperative changes in CDVA at 12, 24, and 36 months follow-up. Abbreviation: CDVA, best-corrected distance visual acuity. 

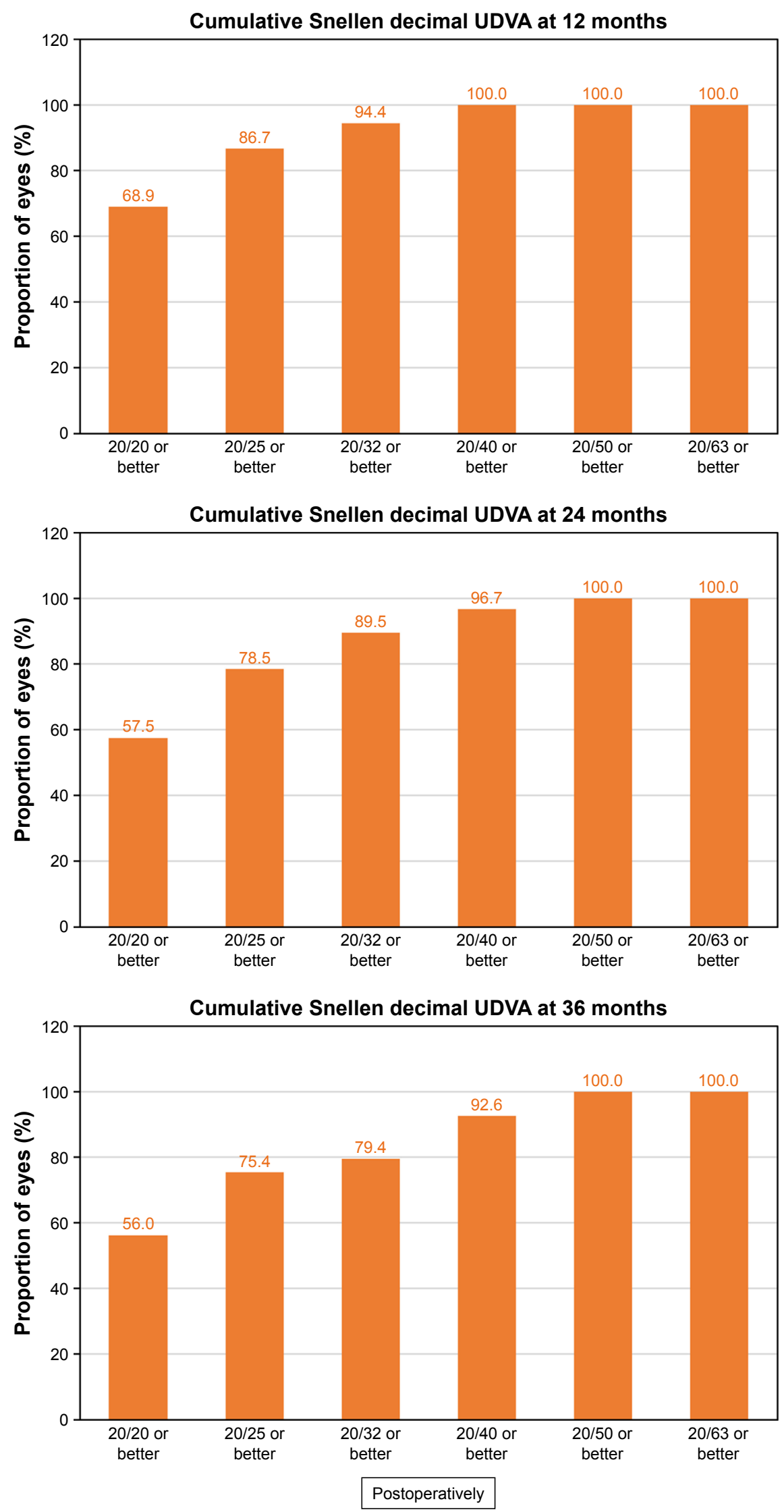

Figure 6 Cumulative proportion of eyes having a given UDVA value at 12, 24, and 36 months postoperatively. Preoperatively, all eyes had an UDVA worse than $20 / 63$. Abbreviation: UDVA, uncorrected distance visual acuity. 

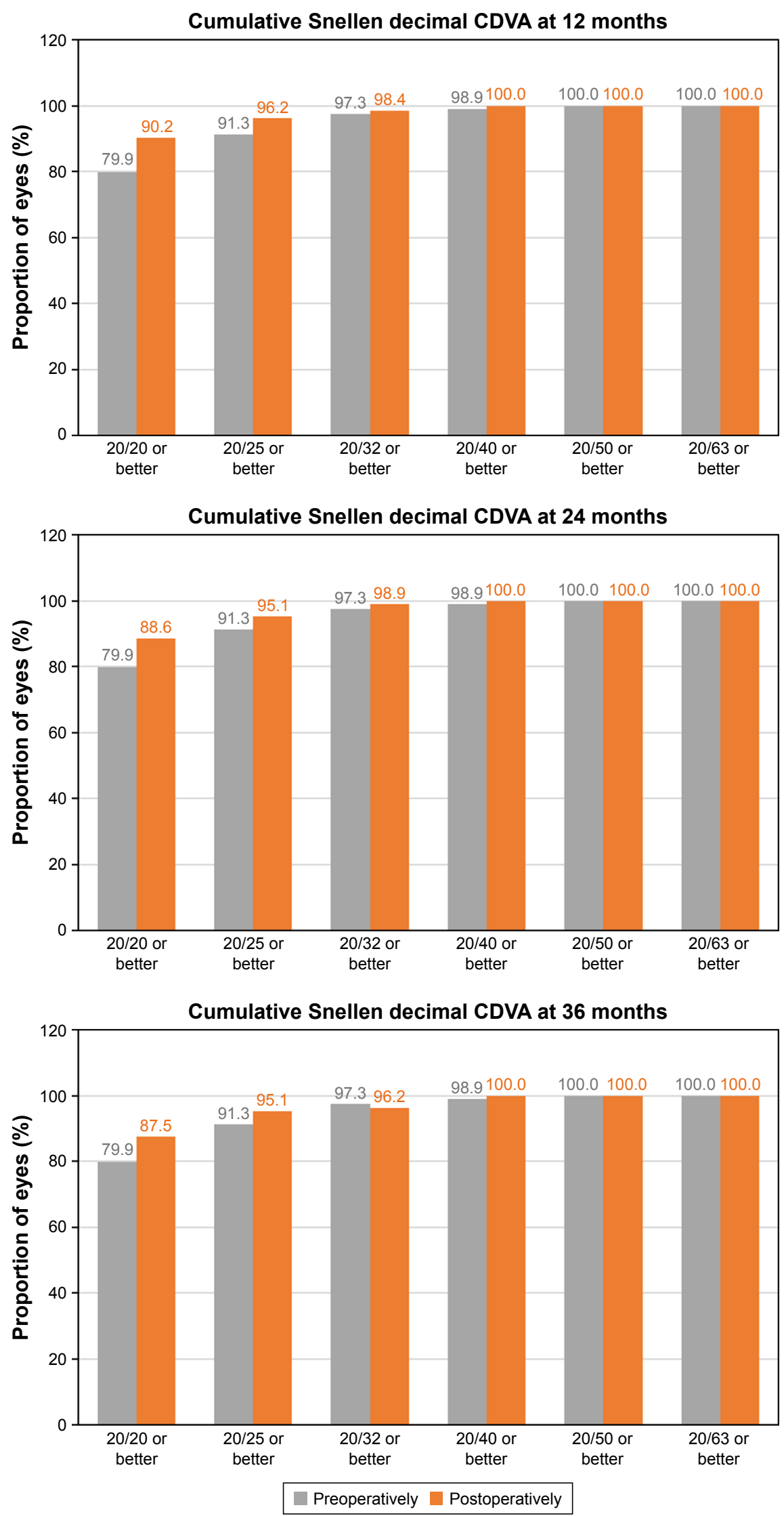

Figure 7 Cumulative proportion of eyes having a given CDVA value, both preoperatively and at I2, 24, and 36 months postoperatively. Abbreviation: CDVA, best-corrected distance visual acuity. 




Figure 8 Evolution of the mean IOP (intraocular pressure), in $\mathrm{mmHg}$ for the whole follow-up period. Error bars represent the SD.

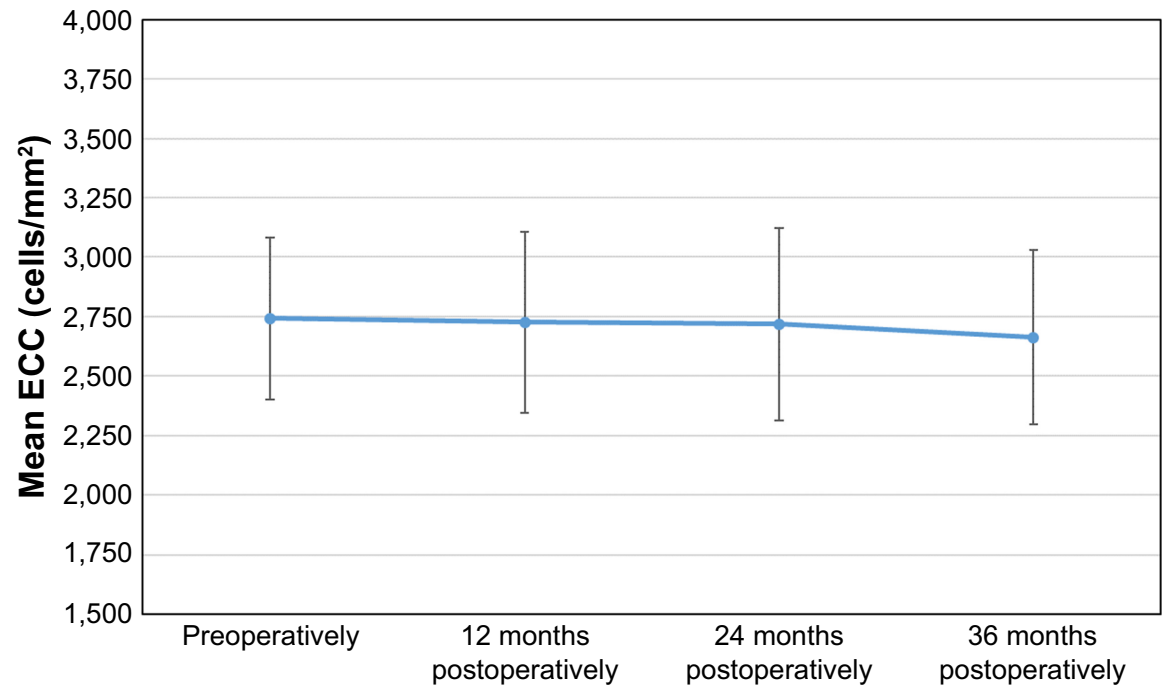

Figure 9 Evolution of the mean ECC, measured in cells $/ \mathrm{mm}^{2}$, for the whole follow-up period. Error bars represent the SD. Abbreviation: ECC, endothelial cell count.

of this long period of follow-up, only $8.9 \%$ of eyes had lost more than two lines of CDVA. The incidence of clinically relevant cataracts $(13.9 \%)$ was significantly linked to the use of the V3 model. Also, they concluded that these ICL models provided good refractive outcomes and stability in the long term. In the study reported by Lee et al,,${ }^{34} 281$ eyes of 145 myopic patients were included with the aim to analyze the long-term (at least 5 years) effectiveness and safety of this surgical option. In their clinical study, the mean SE decreased from $-8.74 \pm 2.27$ to $-0.58 \pm 0.72 \mathrm{D}$, assessing high predictability with $69.8 \%$ and $87.2 \%$ of eyes having a postoperative refraction within \pm 0.5 and $\pm 1.0 \mathrm{D}$, respectively. The final mean $\log$ MAR UDVA and CDVA were $0.02 \pm 0.19$ and $-0.12 \pm 0.13$, respectively, while the mean efficacy and safety indices were $1.04 \pm 0.32$ and $1.20 \pm 0.26$, respectively. They concluded that ICL implantation to correct myopia was an effective and safe surgery with high predictability and stability during the 5-year long-term follow-up. The study performed by Guber et al ${ }^{35}$ included 133 eyes of 78 patients who underwent implantation of V4 and V4 toric ICLs, and they reported the results obtained after 10 years of follow-up. At the end of this period, the mean safety index was $1.25 \pm 0.57$, with a manifest $\mathrm{SE}$ of $-0.7 \mathrm{D}$ in eyes aimed at emmetropia. The mean vault distance decreased from $426 \pm 344 \mu \mathrm{m}$ immediately postoperatively to $213 \pm 169 \mu \mathrm{m}$ at 10 years, and a smaller vault distance was associated with 


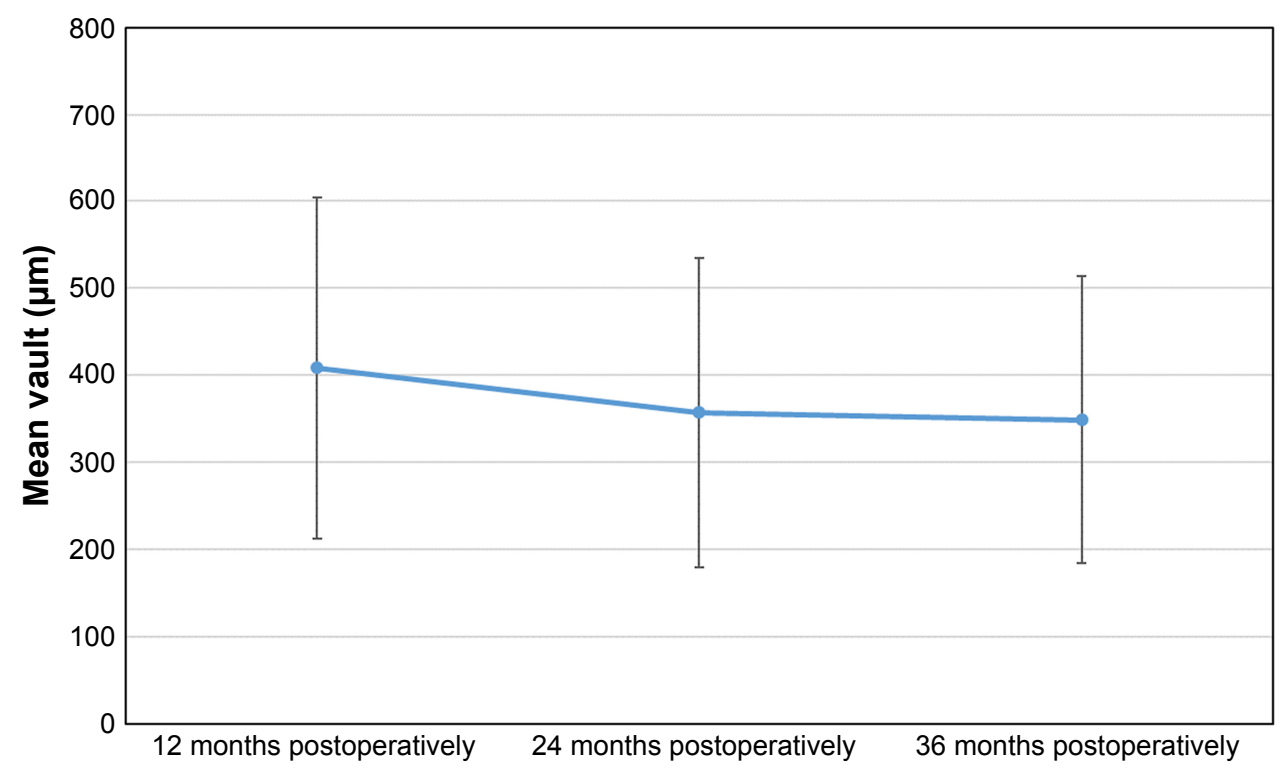

Figure 10 Evolution of the mean vault values, measured in $\mu \mathrm{m}$, for the whole post-surgery follow-up period.

the development of lens opacity and posterior phacoemulsification. According to the authors, the rates of cataract formation at 10 years have important clinical implications, and as such, this information should be part of the available patient information before ICL implantation. Finally, the mean IOP was $15 \mathrm{mmHg}$ immediately postoperatively, and there was no significant increase observed during the 10 years of follow-up. With the results obtained in this retrospective study, the authors concluded that V4 and V4 toric ICL implantation provides good long-term (10-year) safety and stability of refraction in patients with high myopia compared with similar short-term studies.

Regarding the implantation of the V4c model with central hole, most of the comparative studies ${ }^{21-26}$ agreed that the central hole-based ICL appears to be equivalent in the induction of higher-order aberrations, contrast sensitivity function, optical performance including intraocular scattering, UDVA, CDVA, manifest refractive SE, and ECC to previous ICL models for the correction of moderate to high myopia in the short follow-up periods evaluated. Only one study ${ }^{27}$ related possible ring-shaped dysphotopsia to hole ICL implantation, associated with light refraction at the central hole structure.

Recently, an additional clinical study has been reported by Shimizu et $\mathrm{al}^{36}$ to assess the long-term results obtained after the implantation of the V4c ICL model. Examinations were conducted on 64 eyes of 32 consecutive patients in whom implantation of a hole V4c ICL was performed in one eye and that of a conventional ICL was carried out in the other eye by randomized assignment. The mean SE of the patients was $-7.53 \pm 2.39 \mathrm{D}$. The follow-up period extended up to
5 years postoperatively, and the safety, efficacy, predictability, stability, IOP, ECC, and adverse events were assessed and compared over this period. The visual acuity results for logMAR UDVA and CDVA at the end of the follow-up were $-0.17 \pm 0.14$ and $-0.24 \pm 0.08$, respectively, in the $\mathrm{V} 4 \mathrm{c}$ ICL group and $-0.16 \pm 0.10$ and $-0.25 \pm 0.08$, respectively, in the conventional ICL group. In both groups, and at the end of the follow-up period, $96 \%$ and $100 \%$ of eyes, respectively, were within $\pm 1.0 \mathrm{D}$ of the targeted correction. Manifest refraction changed by $-0.17 \pm 0.41$ and $-0.10 \pm 0.26 \mathrm{D}$ from 1 month to 5 years in the V4c and conventional ICL groups, respectively. Only one eye (3.1\%), which was in the conventional ICL group, developed an asymptomatic anterior subcapsular cataract. This study concluded that both V4c and conventional ICLs corrected the ametropia successfully throughout the 5-year follow-up period, and demonstrated that the presence of the central hole in the V4c ICL model does not significantly affect visual and refractive outcomes. In our case, we believe that the aqueous humor flow through the hole lifts the lens (forward the lens) and separates it from the ICL. Higher vaults are obtained compared with the previous V4b model using the same lens calculation technique, and taking into account that cataract is produced by the contact of the ICL with the crystalline lens, we expect to have no cataracts.

The present study, in which the number of eyes included in the 3-year long-term follow-up period has been around the triple of that included in the study reported by Shimizu et $\mathrm{al},{ }^{36}$ shows comparable results, allowing to conclude that V4c ICL long-term implantation is predictable and stable and is a safe and effective procedure to correct ametropia. As pointed out 
by Packer in a recently published meta-analysis and review ${ }^{37}$ on the basis of clinical studies with up to 5 years of follow-up, the new V4c ICL model with central port design provides a significant improvement in vision and quality of life that the ICL makes possible, together with a promise for further reduction of complications.

\section{Acknowledgment}

This study was supported in part by a Staar Surgical grant to the University of Valencia.

\section{Disclosure}

The authors have no proprietary interest in any of the materials mentioned in this article and report no conflicts of interest in this work.

\section{References}

1. Güell JL, Morral M, Kook D, Kohnen T. Phakic intraocular lenses part 1: historical overview, current models, selection criteria, and surgical techniques. J Cataract Refract Surg. 2010;36(11):1976-1993.

2. Schallhorn SC, Farjo AA, Huang D, et al; American Academy of Ophthalmology. Phakic intraocular lens implantation for the correction of myopia; a report by the American Academy of Ophthalmology (Ophthalmic Technology Assessment). Ophthalmology. 2009;116: 2244-2258.

3. Sanders DR, Schneider D, Martin R, et al. Toric implantable collamer lens for moderate to high myopic astigmatism. Ophthalmology. 2007;114(1): $54-61$.

4. Hashem AN, El Danasoury AM, Anwar HM. Axis alignment and rotational stability after implantation of the toric implantable collamer lens for myopic astigmatism. J Refract Surg. 2009;25(10 Suppl): S939-S943.

5. Park SC, Kwun YK, Chung ES, Ahn K, Chung TY. Postoperative astigmatism and axis stability after implantation of the STAAR toric implantable collamer lens. J Refract Surg. 2009;25(5):403-409.

6. Alfonso JF, Baamonde B, Madrid-Costa D, Fernandes P, Jorge J, Montés-Micó R. Collagen copolymer toric posterior chamber phakic intraocular lenses to correct high myopic astigmatism. $J$ Cataract Refract Surg. 2010;36(8):1349-1357.

7. Alfonso JF, Fernández-Vega L, Fernandes P, González-Méijome JM, Montés-Micó R. Collagen copolymer toric posterior chamber phakic intraocular lens for myopic astigmatism: one-year follow-up. J Cataract Refract Surg. 2010;36(4):568-576.

8. Bhikoo R, Rayner S, Gray T. Toric implantable collamer lens for patients with moderate to severe myopic astigmatism: 12-month follow-up. Clin Exp Ophthalmol. 2010;38(5):467-474.

9. Kamiya K, Shimizu K, Aizawa D, Igarashi A, Komatsu M, Nakamura A. One-year follow-up of posterior chamber toric phakic intraocular lens implantation for moderate to high myopic astigmatism. Ophthalmology. 2010;117(12):2287-2294.

10. Mertens EL. Toric phakic implantable collamer lens for correction of astigmatism: 1-year outcomes. Clin Ophthalmol. 2011;5:369-375.

11. Alfonso JF, Lisa C, Alfonso-Bartolozzi B, Pérez-Vives C, MontésMicó R. Collagen copolymer toric phakic intraocular lens for myopic astigmatism: one-year follow-up. J Cataract Refract Surg. 2014;40(7): $1155-1162$.

12. Fernandes P, González-Méijome JM, Madrid-Costa D, Ferrer-Blasco T, Jorge J, Montés-Micó R. Implantable collamer posterior chamber intraocular lenses: a review of potential complications. J Refract Surg. 2011;27(10):765-776.
13. Sánchez-Galeana CA, Zadok D, Montes M, Cortés MA, Chayet AS. Refractory intraocular pressure increase after phakic posterior chamber intraocular lens implantation. Am J Ophthalmol. 2002;134(1): 121-123.

14. Bylsma SS, Zalta AH, Foley E, Osher RH. Phakic posterior chamber intraocular lens pupillary block. J Cataract Refract Surg. 2002;28(12): 2222-2228.

15. Gonvers M, Bornet C, Othenin-Girard P. Implantable contact lens for moderate to high myopia: relationship of vaulting to cataract formation. J Cataract Refract Surg. 2003;29(5):918-924.

16. Sánchez-Galeana CA, Smith RJ, Sanders DR, et al. Lens opacities after posterior chamber phakic intraocular lens implantation. Ophthalmology. 2003;110(4):781-785.

17. Lackner B, Pieh S, Schmidinger G, et al. Long-term results of implantation of phakic posterior chamber intraocular lenses. J Cataract Refract Surg. 2004;30(11):2269-2276.

18. Sanders DR. Anterior subcapsular opacities and cataracts 5 years after surgery in the Visian implantable collamer lens FDA trial. $J$ Refract Surg. 2008;24(6):566-570.

19. Alfonso JF, Lisa C, Abdelhamid A, Fernandes P, Jorge J, Montés-Micó R. Three-year follow-up of subjective vault following myopic implantable collamer lens implantation. Graefes Arch Clin Exp Ophthalmol. 2010;248(12):1827-1835.

20. Fujisawa K, Shimizu K, Uga S, et al. Changes in the crystalline lens resulting from insertion of a phakic IOL (ICL) into the porcine eye. Graefes Arch Clin Exp Ophthalmol. 2007;245(1):114-122.

21. Shimizu K, Kamiya K, Igarashi A, Shiratani T. Early clinical outcomes of implantation of posterior chamber phakic intraocular lens with a central hole (hole ICL) for moderate to high myopia. Br J Ophthalmol. 2012;96(3):409-412.

22. Shimizu K, Kamiya K, Igarashi A, Shiratani T. Intraindividual comparison of visual performance after posterior chamber phakic intraocular lens with and without a central hole implantation for moderate to high myopia. Am J Ophthalmol. 2012;154(3):486.e1-494.e1.

23. Pérez-Vives C, Ferrer-Blasco T, Madrid-Costa D, García-Lázaro S, Montés-Micó R. Optical quality comparison of conventional and HoleVisian implantable collamer lens at different degrees of decentering. Am J Ophthalmol. 2013;156(1):69-76e61.

24. Kamiya K, Shimizu K, Saito A, Igarashi A, Kobashi H. Comparison of optical quality and intraocular scattering after posterior chamber phakic intraocular lens with and without a central hole (hole ICL and conventional ICL) implantation using the double-pass instrument. PLoS One. 2013;8(6):e66846.

25. Pérez-Vives C, Ferrer-Blasco T, Madrid-Costa D, García-Lázaro S, Montés-Micó R. Visual quality comparison of conventional and holeVisian implantable collamer lens at different degrees of decentering. Br J Ophthalmol. 2014;98(1):59-64.

26. Huseynova T, Ozaki S, Ishizuka T, Mita M, Tomita M. Comparative study of 2 types of implantable collamer lenses, 1 with and 1 without a central artificial hole. Am J Ophthalmol. 2014;157(6):1136-1143.

27. Eom Y, Kim DW, Ryu D, et al. Ring-shaped dysphotopsia associated with posterior chamber phakic implantable collamer lenses with a central hole. Acta Ophthalmol. 2017;95(3):e170-e178.

28. Shiratani T, Shimizu K, Fujisawa K, Uga S, Nagano K, Murakami Y. Crystalline lens changes in porcine eyes with implanted phakic IOL (ICL) with a central hole. Graefes Arch Clin Exp Ophthalmol. 2008; 246(5):719-728.

29. Kawamorita T, Uozato H, Shimizu K. Fluid dynamics simulation of aqueous humour in a posterior-chamber phakic intraocular lens with a central perforation. Graefes Arch Clin Exp Ophthalmol. 2012;250(6): 935-939.

30. Thibos LN, Horner D. Power vector analysis of the optical outcome of refractive surgery. $J$ Cataract Refract Surg. 2001;27(1):80-85.

31. Tan WY. Sampling distributions and robustness of $t, F$ and variance-ratio in two samples and ANOVA models with respect to departure from normality. In: Communication in Statistics - Theory and Methods. 1982; 11:486-511. 
32. Gep B. Some theorems on quadratic forms applied in the study of analysis of variance problems. II: Effects of inequality of variance and of correlation between errors in the two-way classification. Annals of Mathematical Statistics. 1965;25:484-498.

33. Moya T, Javaloy J, Montés-Micó R, Beltrán J, Muñoz G, Montalbán R. Implantable collamer lens for myopia: assessment 12 years after implantation. J Refract Surg. 2015;31(8):548-556.

34. Lee J, Kim Y, Park S, et al. Long-term clinical results of posterior chamber phakic intraocular lens implantation to correct myopia. Clin Exp Ophthalmol. 2016;44(6):481-487.

35. Guber I, Mouvet V, Bergin C, Perritaz S, Othenin-Girard P, Majo F. Clinical outcomes and cataract formation rates in eyes 10 years after posterior phakic lens implantation for myopia. JAMA Ophthalmol. 2016; 134:487-494.
36. Shimizu K, Kamiya K, Igarashi A, Kobashi H. Long-term comparison of posterior chamber phakic intraocular lens with and without a central hole (hole ICL and conventional ICL) implantation for moderate to high myopia and myopic astigmatism: consort-compliant article. Medicine. 2016;95(14):e3270.

37. Packer M. Meta-analysis and review: effectiveness, safety, and central port design of the intraocular collamer lens. Clin Ophthalmol. 2016; 10:1059-1077.
Clinical Ophthalmology

\section{Publish your work in this journal}

Clinical Ophthalmology is an international, peer-reviewed journal covering all subspecialties within ophthalmology. Key topics include: Optometry; Visual science; Pharmacology and drug therapy in eye diseases; Basic Sciences; Primary and Secondary eye care; Patien Safety and Quality of Care Improvements. This journal is indexed on

Submit your manuscript here: http://www.dovepress.com/clinical-ophthalmology-journal

\section{Dovepress}

PubMed Central and CAS, and is the official journal of The Society of Clinical Ophthalmology (SCO). The manuscript management system is completely online and includes a very quick and fair peer-review system, which is all easy to use. Visit http://www.dovepress.com/ testimonials.php to read real quotes from published authors. 